Clinical Medicine

Poster

Abstract ID: 139

\title{
Post concussion syndrome after mild traumatic brain injury in a single neurosurgical center in East Coast, Malaysia - A preliminary report
}

\author{
Mohamed Saufi Awang ${ }^{\mathrm{a}} \mid$ Buveinthiran Balakrishnan $^{\mathrm{a}} \mid$ Chan Kin Hup $^{\mathrm{a}} \mid$ Razman Mohd Rus $^{\mathrm{b}}$ \\ ${ }^{a}$ Department of Surgery, Kulliyyah of Medicine, International Islamic University Malaysia \\ ${ }^{b}$ Department of Community Medicine, Kulliyyah of Medicine, International Islamic University \\ Malaysia
}

Introduction: Mild traumatic brain injury is the most common form of traumatic brain injury. Individuals sustaining mild head injuries often complain of a cluster of symptoms termed post concussion syndrome. Post concussion syndrome can be profoundly disabling. Thus the aim of this study is to determine the prevalence of post concussion syndrome in an adult population with mild traumatic brain injury in a single neurosurgical center in East Coast, Malaysia. Methods: Cross Sectional study, in a single neurosurgical center in Kuantan, Pahang. The study period is from January 2016 - December 2016. Universal sampling method was used, all patients with mild traumatic brain injury presenting to HTAA, meeting the inclusion and exclusion criteria is included in this study. Patients are then subjected to the checklist for diagnosis of post concussion syndrome as per ICD 10 classification at 2 weeks interval. Results: Between February 2016 - June 2016, a total of 136 patients with mild traumatic injury have been recruited to this study. The leading cause of mild traumatic brain injury is road traffic accidents, 86 patients $(63.2 \%)$, and the mean age of this patient with mild traumatic brain injury is 28.8 . Out of this number, 11 patients $(8.1 \%)$ have been diagnosed with post concussion syndrome. Conclusions: The majority of individuals who sustain mild traumatic brain injuries are young adults, and the most common cause is road traffic accidents. Less than $10 \%$ of recruited patients suffered from post concussion syndrome.

KEYWORDS: mild head injury, post concussion syndrome, trauma 